\title{
Avoidance learning as a function of time after fear conditioning and unsignalled shock
}

\author{
F. Robert Brush 2 \\ UNIVERSITY OF PENNSYLVANIA
}

\begin{abstract}
Abstraet
Relearning of an incompletely learned shuttlebox avoidance response in rats is a U-shaped function of the time after completion of original training. Three experiments are reported which show that fear conditioning is the component of original training that is necessary and sufficient to produce the U-shaped function.
\end{abstract}

\section{Problem}

A number of experiments (Brush et al, 1963; Denny, 1958; Denny \& Thomas, 1960; Denny \& Ditchman, 1962) have replicated the rather startling finding, first reported by Kamin (1957), that retention of an incompletely learned avoidance response, as measured by relearning, is a $\mathrm{U}$-shaped function of the time separating the original and retraining sessions (intersession interval). We have shown (1963) that neither pseudoconditioning nor escape from unsignalled shock is sufficient to produce the U-shaped function, and that instrumental avoidance of shock is not a necessary feature of original training. We suggested, therefore, that fear conditioning is necessary and sufficient to produce the intersession interval effect. The experiment reported here confirms this idea.

\section{Method}

All conditioning and training occurred in automatic shuttleboxes whose essential features have been described elsewhere (Brush, 1962; Brush \& Knaff, 1959). The CS was an increase in illumination and presentation of a $78 \mathrm{db}$ white noise $(8 \mathrm{db}$ above the ambient noise level) in the compartment occupied by the rat. The US was a scrambled ac shock of 0.3 ma. The subjects were experimentally naive male hooded rats (Long-Evans strain), and each animal received a sequence of original training, intersession interval, and retraining. For different groups of subjects original training consisted of 25 trials of (1) escape training, $N=50$; (2) fear conditioning, $\mathrm{N}=136$ in three replications; or (3) unsignalled shock, $\mathrm{N}=92$ in two replications. In escape training the CS-US interval was $0.5 \mathrm{sec}$. and both CS and US were terminated by the instrumental escape response of running to the opposite compartment. In the fear conditioning procedure the same CS-US interval was used, and both CS and US terminated simultaneously. The US, however, had a fixed duration of $0.5 \mathrm{sec}$. per trial, and the animal was confined to one of the compartments of the shuttlebox so that the US could not be instrumentally terminated. In the unsignalled shock procedure no CS was used, and, as in fear conditioning, the US duration was 0.5 sec.; these animals were also confined to one compartment of the shuttlebox.

The subjects in each experimental group were divided

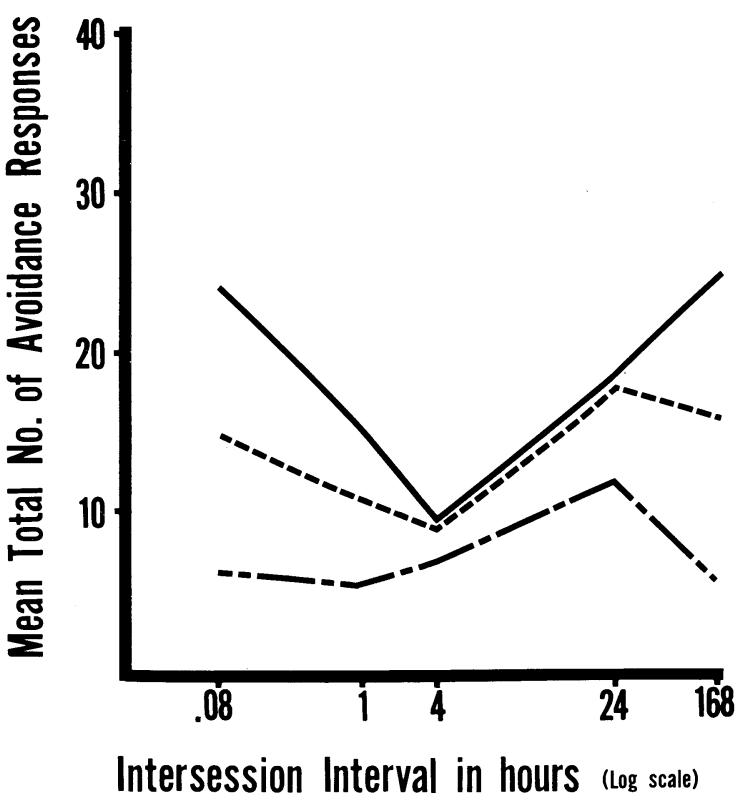

Fig. 1. Mean total number of avoidance responses during retraining as a function of time after escape training (-), fear conditioning (_ _ ) and unsignalled shock (_. - _).

into five subgroups of equal or nearly equal size and one subgroup was assigned to each of the following intersession intervals: $.08,1,4,24,168 \mathrm{hr}$. Each animal spent the intersession interval in its home cage and was then returned to the shuttlebox for the retraining session. This always consisted of 40 trials of avoidance training in which a delayed-conditioning procedure with a 5-sec. CS-US interval was used. A 1-min. intertrial interval was used throughout original and retraining sessions.

\section{Results}

Figure 1 shows the mean total number of avoidance responses made by each group during the retraining session as a function of the intersession interval. The top function shows clearly that the intersession interval effect is obtained following escape training with a short CS-US interval; this replicates earlier research (Brush et al, 1963) which used a different CS. An analysis of variance for trend showed that the effect of intersession interval is significant $(p<.05)$ and nonlinear $(p<.05)$. It should be noted, however, that this function has its minimum at $4 \mathrm{hr}$., whereas most of the functions reported in the literature have minima at $1 \mathrm{hr}$. Although there is no adequate explanation of this shift in the minimum, it is likely that a contributing factor is the moderate rate of learning porduced by the conditions of this experiment. Kamin (1963) has shown, for example, that the 
function generated by slow learners has a minimum a 6 rather than $1 \mathrm{hr}$.

The middle curve of Fig. 1 presents the intersession interval function that follows fear conditioning. A treatment by replication analysis of variance showed that the main effect of intersession interval is significant $(p<.01)$, and that neither the replication effect nor the interval by replication interaction is significant $(F=$ $1.17 ; \mathrm{df}=2 / 121 ; \mathrm{F}=1.56 ; \mathrm{df}=8 / 121$, respectively). An analysis of variance for trend showed that the function is significantly nonlinear $(p<.05)$. Although the notable reversal in the 168-hr. group contributes to this nonlinearity, the function determined by the first four intervals is also nonlinear $(p<.01)$. These data establish unequivocally that fear conditioning is sufficient to produce the $\mathrm{U}$-shaped intersession interval function. Kamin's (1963) failure to find this function is presumably attributable to an unfortunate selection of temporal or other parameters of fear conditioning.

The bottom function in Fig. 1 shows that fear conditioning is also necessary to produce the U-shaped function because it does not occur when the CS is removed from the fear conditioning procedure although intensity and duration of shock are held constant. A treatment by replication analysis of variance of these data indicated that there are no significant effects of intersession interval $(F=1.78 ; d f=4 / 82 ; p>.10)$, of replication $(F<1.0)$, or of interval by replication inter-1 action $(F<1.0)$. There is a tendency, however, for the function to increase during the 24-hr. period following unsignalled shock, and then to decrease during the following week. Analysis of variance showed also that the: three functions in Fig. 1 are different from each other $(\mathrm{p}<.01)$.

\section{Diseussion}

To account for the intersession interval effect we have postulated $(1963,1964)$ that a "parasympathetic over-reaction" follows the termination of fear conditioning. It was argued that Ss would be ill-equipped to deal with the stress of avoidance training if it were initiated at the peak of such an over-reaction, e. g.,
1 to $4 \mathrm{hr}$. after conditioning. It was noted also that this over-reaction must be peculiarly dependent upon fear conditioning. The data presented here are consistent. with such an interpretation. More importantly, however, they require the assertion that the mechanism underlying the U-shaped intersession interval function is initiated by fear conditioning and is not a general reaction to painful stimulation.

As original training changed from escape training through fear conditioning to unsignalled shock, avoidance learning became progressively poorer. A common elements notion of transfer of training is sufficient to account for this result. It should be noted, however, that these data also indicate that both learning of instrumental responses and classical conditioning of emotion significantly influence the early and persistent occurrence of the instrumental avoidance response during subsequent training.

\section{References}

BRUSH, F. R. The effects of intertrial interval on avoidance learning in the rat.J. comp. physiol. Psychol., 1962, 55, 888-892.

BRUSH, F. R., \& KNAFF, P. R.A device for detecting and controlling automatic programming of avoidance conditioning in a shuttlebox. Amer. J. Psychol., 1959, 72, 275-278.

BRUSH, F. R., MYER, J. S., \& PALMER, M. E. Effects of kind of prior training and intersession interval upon subsequent avoidance learning. J. comp. physiol. Ṕsychol., 1963, 56, 539-545.

BRUSH, F. R., MYER, J.S., \& PALMER, M. E. Joint effects of intertrial and intersession interval upon avoidance learning. Psychol. Rep., 1964, 14, 31-37.

DENNY, M. R. The "Kamin Effect" in avoidance conditioning. Amer. Psychologist, 1958, 13, 419. (Abstract)

DENNY, M. R., \& THOMAS, J. O. Avoidance learning and relearning as a function of shuttlebox dimensions. Science, $1960,132,620-621$.

DENNY, M. R., \& DITCHMAN, R. E. The locus of maximal "Kamin Effect" in rats. J.comp. physiol. Psychol., 1962, 55, 1069-1070.

KAMIN, L. J. The retention of an incompletely learned avoidance response. J. comp. physiol. Psychol., 1957, 50, 457-460.

KAMIN, L. J. Retention of an incompletely learned avoidance response: some further analysis. J.comp. physiol. Psychol., 1963, 56, 713-718.

Notes

1. This research was supported by Grant $\mathrm{MH}-03337$ from the National Institute of Mental Health, United States Public Health Service. 2. Visiting Scientist, Regional Primate Research Center, University of Wisconsin, 1964-1965. 